\title{
EFEITO DO POLIETILENOGLICOL E DA ALBUMINA NA IMOBILIZAÇÃO DE LIPASE MICROBIANA E NA CATÁLISE EM MEIO ORGÂNICO
}

\author{
Cleide Mara Faria Soares e Maria Helena Andrade Santana
}

Departamento de Processos Biotecnológicos, Faculdade de Engenharia Química, Universidade Estadual de Campinas, CP 6066, 13081-970 Campinas- SP

Gisella M. Zanin

Departamento de Engenharia Química, Universidade Estadual de Maringá, Av. Colombo, 5790, 87020-900 Maringá - PR

Heizir F. de Castro*

Departamento de Engenharia Química, Faculdade de Engenharia Química de Lorena, CP 116, 12606-970 Lorena - SP

Recebido em 10/12/02; aceito em 15/5/03

\begin{abstract}
EFFECT OF POLY (ETHYLENE) GLYCOL AND ALBUMIN ON THE IMMOBILIZATION OF MICROBIAL LIPASE AND CATALYSIS IN ORGANIC MEDIA. Poly (ethylene) glycol (PEG) and bovine serum albumin (BSA), as additive agents, were used to enhance the activity of immobilized microbial lipase in organic solvent. Controlled pore silica (CPS) was selected as matrix and different immobilization procedures were evaluated: directly lipase binding on CPS and simultaneous addition of lipase and additive agent on the same support. The highest coupling yield (59.6\%) was attained when the immobilization procedure was performed at lipase loading of $150 \mathrm{U} / \mathrm{g}$ support in the presence of PEG-1.500. This immobilized system was used in esterification reactions under repeated batch cycles and the biocatalyst half-life was found to increase 2.7 times when compared with the control.
\end{abstract}

Keywords: additives; controlled pore silica; immobilized lipase.

\section{INTRODUÇÃO}

Diversos trabalhos descrevem um melhoramento significativo na atividade e estabilidade de enzimas imobilizadas, quando o procedimento de imobilização é realizado em presença de aditivos ${ }^{1-3}$. A maioria desses estudos envolve a co-imobilização do aditivo em processo de adsorção simples (ou parcialmente modificado por precipitação da enzima, por evaporação da água, ou por liofilização), sendo alguns efeitos atribuídos a esta nova técnica: (i) proteção da inativação da enzima durante a etapa de imobilização; (ii) retenção da camada de água ao redor do biocatalisador ${ }^{4}$ e (iii) efeitos dispersantes das moléculas da enzima e facilitadores de transporte de massa quando aditivos são usados como matrizes de imobilização ${ }^{5}$. $\mathrm{O}$ aditivo pode estar presente ou ausente no meio de dispersão. $\mathrm{O}$ contato do aditivo com o suporte e com a enzima pode apresentar comportamento antagônico, isto é, a interação do sistema (aditivo + suporte + enzima) pode ser suficiente ou apresentar um efeito negativo na reação de interesse ou resistência da transferência de massa. A influência do aditivo na atividade enzimática ainda não está totalmente esclarecida ${ }^{5}$.

Nem todos os aditivos são eficientes como estabilizantes. A seleção do aditivo adequado é função do tipo de enzima e do método de imobilização. No caso específico das lipases, que exigem uma interface para sua total atividade catalítica, o uso de aditivos macromoleculares tem mostrado efeitos estabilizantes significativos, por meio do revestimento da interface impedindo, desta forma, uma mudança de sua estrutura proteica. Segundo Bosley ${ }^{6}$, caseína, gelatina, albumina de ovo ou bovina são aditivos eficientes para imobilização de lipases em vários suportes. Resultados similares foram descritos por Reetz et al. ${ }^{3}$, sendo também recomendado o uso de outros tipos de aditivos

*e-mail: heizir@dequi.faenquil.br macromoleculares, como por exemplo, polietilenoglicol e álcool polivinílico. Outro parâmetro que também interfere na eficiência de um determinado aditivo é referente à sua forma de adição no procedimento de imobilização, ou seja, em que etapa esta adição é mais indicada e qual a massa de aditivo necessária para promover uma estabilização satisfatória. Com relação ao primeiro fator, num estudo detalhado realizado por Wehtje et al. ${ }^{2}$ é sugerido que a adição de aditivos seja efetuada antes da adição de enzima ou simultaneamente com a enzima. A adição de aditivos depois da enzima ter sido imobilizada ao suporte não apresentou efeito benéfico. Quanto à massa de aditivo, Wehtje et $a .^{2}$ também recomendaram uma avaliação experimental em função do tipo de aditivo usado, tendo em vista que o efeito do aditivo depende de sua massa molecular.

Zanin $^{7}$ e Baron et al. ${ }^{8}$ imobilizaram amiloglicosidase e inulinase em sílica de porosidade controlada e avaliaram o desempenho dos derivados imobilizados em reator de leito fixo e fluidizado, operando de forma contínua. As boas características operacionais apresentadas pela sílica, como matriz, serviram de base para a escolha desse suporte para a imobilização de lipase microbiana de Candida rugo$s a$, em trabalho desenvolvido por Soares et al. ${ }^{9}$, no qual foram caracterizadas as condições ótimas de $\mathrm{pH}$ e temperatura, bem como a estabilidade térmica e operacional do biocatalisador. Apesar dos resultados satisfatórios, foi constatada uma baixa estabilidade operacional dos derivados imobilizados. Para contornar esse problema, tornouse necessário estudar estratégias para proteger a enzima de efeitos de agregação ou desnaturação que ocorreram devido à presença dos silanos usados durante a formação da matriz de sílica, o que motivou o desenvolvimento do presente trabalho. Resultados da literatura indicam um considerável aumento da atividade lipolítica, por meio do tratamento do suporte com aditivos, reduzindo, desta forma, a desativação da enzima por interações lipase-suporte ${ }^{1-5}$. Tomando por base essas informações e considerando as inúmeras variáveis envolvidas nesse procedimento, optou-se pelo uso da ferramenta do pla- 
nejamento experimental para seleção do aditivo mais eficiente para obtenção de derivados imobilizados de lipase em sílica de porosidade controlada ativos e estáveis.

\section{PARTE EXPERIMENTAL}

\section{Materiais}

Os experimentos foram realizados com lipase de origem microbiana de Candida rugosa, com atividade específica de 1440 U/mg de proteína (Bradford) ${ }^{10}$ adquirida da Sigma Chemical Co. (St. Louis, MO, EUA). Como suporte foi utilizado sílica de porosidade controlada (SPC) adquirida da Corning Glass Works, EUA, código 691952, com diâmetro médio de poro de $37,5 \mathrm{~nm}$ e granulometria na faixa de 30/45 mesh $(0,589$ a $0,354 \mathrm{~mm}) . \gamma$ aminopropiltrietóxi silano ( $\gamma$-APTS), glutaraldeído $(25 \% \mathrm{v} / \mathrm{v})$, albumina (ABS) foram adquiridos da Sigma Chemical Co. (St. Louis, MO, EUA). Polietilenoglicol (PEG, MM 1.500 e 10.000, Synth, São Paulo, Brasil). Azeite de oliva (baixa acidez) foi comprado em mercado local. Substratos para as reações de esterificação (n-butanol, $98 \%$, Merck) e ácido butírico (95\%, Vetec, São Paulo, Brasil) foram desidratados com peneira molecular (silicato de alumínio e sódio, tipo 13 X-BHD Chemicals, Toronto, Canada). Todos os outros reagentes foram de grau analítico.

\section{Imobilização da lipase em sílica de porosidade controlada}

A sílica foi previamente tratada com $\gamma$-aminopropiltrietóxi silano $(\gamma$-APTS) e ativada com glutaraldeído, de acordo com metodologia desenvolvida anteriormente ${ }^{9}$. O procedimento de imobilização consistiu do contato da solução enzimática com o suporte e agentes estabilizantes, por um período de $24 \mathrm{~h}$. Para cada grama de suporte seco, foram adicionados massas adequadas de lipase (150-450 U) dissolvidas em água e $200 \mu \mathrm{L}$ de solução aquosa contendo $50 \mathrm{mg}$ de aditivo/mL (PEG-10.000, PEG-1.500 ou ABS) sob condições de agitação controlada durante $3 \mathrm{~h}$. Em seguida, $10 \mathrm{~mL}$ de hexano foram adicionados e a mistura enzima-suporte-aditivo foi incubada à temperatura de $4{ }^{\circ} \mathrm{C}$ durante $21 \mathrm{~h}$. A enzima imobilizada foi recuperada por filtração a vácuo e o sistema imobilizado lavado com hexano para remoção da lipase não adsorvida no suporte. Nos filtrados, foram analisados os teores de proteínas totais e nos derivados imobilizados, quantificados os teores de água e atividade hidrolítica. O rendimento de imobilização ( $\eta \%)$ calculado pela Equação 1.

$n(\%)=\frac{U s}{U o} \times 100$

onde: $U s=$ unidades de atividade enzimática total presente no suporte e $U_{0}=$ unidades de atividade utilizadas na imobilização.

\section{Delineamento experimental}

Para avaliação da eficiência de retenção da lipase em SPC, na presença de estabilizantes, foi adotada a metodologia do planejamento experimental empregando duas matrizes $2^{2}$ com face centrada ${ }^{11}$. Os aditivos $\left(x_{1}\right)$ foram avaliados em função da concentração de lipase $\left(x_{2}\right)$, adotando como variável resposta o rendimento de imobilização ( $\eta \%)$. A análise estatística dos resultados foi realizada utilizando-se o programa STATGRAPHICS versão 6.0. Modelos foram determinados por regressão linear pelo método dos mínimos quadrados aplicada aos resultados experimentais obtidos nos planejamentos fatoriais, como representados na Equação 2.

$$
Y i=b o \sum_{i=1}^{n} b i X i+\sum_{i=1}^{n} b i i X i i+\sum_{i=1}^{n} \sum_{j=i+j}^{n} b i j X i X j
$$

onde $\mathrm{Y}_{\mathrm{i}}$ representa a variável resposta, $\mathrm{b}_{0}, \mathrm{~b}_{\mathrm{i}}, \mathrm{b}_{\mathrm{ii}}, \mathrm{b}_{\mathrm{ij}}$ representam os coeficientes da regressão; $\mathrm{X}_{\mathrm{i}}, \mathrm{X}_{\mathrm{j}}$ representam as variáveis estudadas.

\section{Determinação da atividade de hidrólise}

A atividade enzimática das lipases nas formas livre e imobilizada foi determinada pelo método de hidrólise do azeite de oliva, conforme metodologia modificada por Soares et al. ${ }^{9}$. Os ácidos graxos liberados foram titulados com solução de $\mathrm{KOH} 20 \mathrm{mM}$, utilizando fenolftaleína como indicador. Uma unidade de atividade foi definida como a quantidade de enzima que libera $1 \mu \mathrm{mol}$ de ácido graxo por minuto de reação, nas condições do ensaio. Para cada análise de atividade, foi realizado um controle utilizando $200 \mathrm{mg}$ do suporte seco. As atividades foram expressas em $\mu \mathrm{mol} / \mathrm{mg}$ min (U), sendo que miligrama refere-se à massa de sólido para a lipase livre e suporte seco para a lipase imobilizada.

\section{Determinação da atividade de esterificação}

A atividade de esterificação da lipase imobilizada em SPC foi determinada pela formação do butirato de butila na reação de nbutanol (300 mM) com ácido butírico (300 mM) em heptano $(20 \mathrm{~mL})$, a $37^{\circ} \mathrm{C}$ com massa seca de enzima igual a $0,85 \mathrm{~g}$. Alíquotas de $1 \mathrm{~mL}$ foram retiradas do meio reacional no tempo inicial e após intervalos pré-determinados. A concentração de butirato de butila foi quantificada por cromatografia em fase gasosa (Cromatógrafo Varian 3800), empregando a coluna 6ft S\# DEGS WHP 80/100 mesh a $60{ }^{\circ} \mathrm{C}$ e hexanol como padrão interno. $\mathrm{O}$ gás de arraste foi o nitrogênio, mantido num fluxo $30 \mathrm{~mL} / \mathrm{min}$ no interior da coluna, valor ideal para eficiência da coluna. Uma unidade de atividade (esterificação) foi definida como a quantidade de enzima que conduz à formação de $1 \mu \mathrm{mol}$ de butirato de butila por minuto nas condições do ensaio.

\section{Estabilidade operacional}

A estabilidade operacional do sistema imobilizado foi verificada na síntese de butirato de butila, sob regime de bateladas consecutivas, com reutilização do sistema imobilizado e utilizando 1,0 g (massa seca) de lipase imobilizada e $20 \mathrm{~mL}$ de substrato nas mesmas concentrações adotadas para determinação de atividade de esterificação. As reações foram realizadas em um reator batelada, com agitação, provido de uma cesta construída em tela de aço inox, malha 100 $(0,147 \mathrm{~mm})$ com altura de $65 \mathrm{~mm}$ e diâmetro de $12 \mathrm{~mm}$. Esta foi suportada em uma placa de alumínio, com orifício central, colocada na parte superior do reator. As bateladas $\left(24 \mathrm{~h} / 37^{\circ} \mathrm{C}\right)$ foram monitoradas nos tempos iniciais e finais. Entre as bateladas, a lipase imobilizada foi lavada com $20 \mathrm{~mL}$ de hexano para remoção dos reagentes e produtos eventualmente retidos no suporte. Após $1 \mathrm{~h}$, tempo necessário para evaporação do solvente, a preparação de lipase imobilizada foi reutilizada empregando substrato na mesma concentração utilizada anteriormente. A atividade de esterificação foi calculada no final de cada ciclo. A constante de inativação $\left(\mathrm{k}_{\mathrm{d}}\right)$ foi calculada pela Equação 3 e o tempo de meia-vida pela Equação 4.

$$
\begin{aligned}
& \mathrm{A}=\mathrm{A}_{0} \exp \cdot\left(-\mathrm{k}_{\mathrm{d}} \cdot \mathrm{t}\right) \\
& \mathrm{t}_{1 / 2}=\ln 0,5 /-\mathrm{k}_{\mathrm{d}}
\end{aligned}
$$

onde: $\mathrm{A}_{0}=$ atividade inicial, $\mathrm{A}=$ atividade final, $\mathrm{t}=$ tempo, $\mathrm{t}_{1 / 2}=$ tempo de meia-vida e $\mathrm{k}_{d}=$ constante de desativação. 


\section{RESULTADOS E DISCUSSÃO}

\section{Efeito do aditivo no rendimento de imobilização de lipase em} sílica de porosidade controlada

Lipase de Candida rugosa foi imobilizada por ligação covalente em sílica sinalizada e ativada com glutaraldeído empregando diferentes relações entre enzima e suporte, na ausência e presença de agentes estabilizantes. Esses experimentos foram realizados adotando dois planejamentos fatoriais completos $2^{2}$ com face centrada ${ }^{11}$, constituídos de 9 ensaios em cada matriz. Os aditivos (ABS, PEG10.000 e PEG-1.500) foram avaliados como fatores qualitativos, nas duas matrizes. Para a matriz A (aditivos PEG-10.000 e ABS) o sinal (-) representa a presença de PEG-10.000 e o sinal (+) a presença de ABS, enquanto para a matriz B o sinal (-) representa a presença de PEG-10.000 e o sinal (+) a presença de PEG-1.500. A variável concentração de lipase foi mantida constante nas duas matrizes, nas quais o sinal (-) corresponde ao nível baixo (150 U/g de sílica), o sinal (+) o nível alto (450 U/g de sílica) e o sinal (0) o ponto central (300 U/g de sílica).

Desta forma, em cada matriz foram realizados nove ensaios, dos quais cinco foram referentes aos pontos centrais. Esta metodologia permitiu obter uma estimativa do erro experimental associado à determinação de uma resposta individual. A extensão do erro é importante para verificar se os efeitos são estatisticamente significativos ${ }^{11}$.

$\mathrm{Na}$ Tabela 1 estão apresentadas as duas matrizes experimentais juntamente com os resultados obtidos para cada matriz. As atividades hidrolíticas dos derivados imobilizados variaram entre 17,7 a 198,5 U/mg de suporte, correspondendo a rendimentos de imobilização de 7,10 a $59,6 \%$. Isto sugere que o rendimento de imobilização depende do tipo de aditivo utilizado e da concentração de lipase.

A influência dos aditivos na atividade hidrolítica do derivado imobilizado (U/mg) e rendimento de imobilização obtido ( $\eta \%)$, em função da concentração de lipase utilizada na etapa de imobilização pode ser melhor visualizada nas Figuras 1a-d.

Quando a lipase foi imobilizada em SPC na ausência de aditivos (controle, Figura 1a), os rendimentos de imobilização variaram entre 10,1 a $17,3 \%$ e o valor mais elevado foi obtido para uma concentração de lipase de $300 \mathrm{U} / \mathrm{g}$ de suporte. Esses resultados indicam que, para concentrações superiores a $300 \mathrm{U} / g$ de suporte, ao invés de se obter uma maior porcentagem fixação de lipase na superfície do suporte pode ter ocorrido uma adsorção de camadas múltiplas, blo- queando ou inibindo o acesso do substrato (emulsão de azeite de oliva) ao sítio ativo da lipase. Resultados similares são relatados por diversos pesquisadores, para procedimentos de imobilização de lipase em materiais silícicos e seus derivados ${ }^{2,3,9}$.

A utilização de albumina (Figura 1b) promoveu um aumento no rendimento de imobilização em relação ao controle (ausência de aditivos) e esse efeito foi mais pronunciado no nível alto de lipase do que no nível baixo (32,2 contra 23,6\%). O valor máximo de atividade lipolitíca 153,2 U/mg de suporte foi obtido para uma concentração de lipase da ordem de $450 \mathrm{U} / \mathrm{g}$ de suporte. Por outro lado, quando o PEG-10.000 foi utilizado como aditivo (Figura 1c) foi constatado um comportamento inverso, pois rendimentos de imobilização mais elevados $(15,6 \%)$ foram obtidos no nível baixo de enzima (150 U/g de suporte). O aumento da concentração de lipase para o nível alto (450 U/g de suporte) reduziu o rendimento de imobilização para $7,1 \%$, evidenciando o efeito negativo desse aditivo. Os baixos rendimentos da imobilização obtidos com PEG-10.000 são interpretados na literatura como função da massa molecular do PEG, isto é, quanto maior a massa molecular do PEG menor o rendimento de imobilização ${ }^{3,5}$. Além do tamanho da cadeia de hidrocarbonetos influenciar diretamente as forças de repulsão entre as matrizes poliméricas, o aumento da viscosidade do meio de imobilização pode restringir a flexibilidade das cadeias da enzima na formação das matrizes 5 .

Para verificar o efeito negativo do PEG-10.000, no rendimento de imobilização da lipase em SPC, foram efetuados ensaios complementares (matriz B), permitindo uma comparação da atuação do polietilenoglicol com diferentes massas moleculares. Verifica-se na Figura 1d, que a utilização do PEG-1.500 foi efetiva para todas as concentrações de lipase testadas, sendo obtido um valor máximo de atividade lipolitíca de 198,5 U/mg de suporte para uma concentração de lipase da ordem de $450 \mathrm{U} / \mathrm{g}$ de suporte. Esse valor representa um aumento de 4 vezes em relação ao controle. Com base nos resultados, observa-se uma tendência experimental e um comportamento definido, demonstrando, em termos gerais, que a utilização do PEG com menor massa molecular (1.500) aumenta significativamente o rendimento de imobilização da lipase em SPC. Este desempenho é similar ao descrito por Rocha et al. ${ }^{5}$, que também observaram um aumento na atividade catalítica do derivado imobilizado com a redução da massa molecular do PEG. O rendimento mais elevado $(59,6 \%)$ foi obtido quando PEG-1.500 foi utilizado como agente estabilizante, produzindo uma preparação catalítica altamente ativa $(109,5 \mathrm{U} / \mathrm{mg})$

Tabela 1. Atividade hidrolítica (U/mg) e rendimentos de imobilização ( $\eta \%)$ de acordo com as matrizes experimentais da lipase em sílica de porosidade controlada na presença de aditivos

\begin{tabular}{|c|c|c|c|c|c|c|c|c|c|c|}
\hline \multirow{3}{*}{ Ensaio } & \multirow{2}{*}{\multicolumn{2}{|c|}{$\begin{array}{l}\text { Variáveis } \\
\text { codificadas }\end{array}$}} & \multicolumn{4}{|c|}{ Matriz A } & \multicolumn{4}{|c|}{ Matriz B } \\
\hline & & & \multirow[t]{2}{*}{ Aditivo } & \multirow{2}{*}{$\begin{array}{c}\text { Concentração } \\
\text { de lipase } \\
\text { (U/g suporte) }\end{array}$} & \multirow{2}{*}{$\begin{array}{c}\text { Atividade } \\
\text { (U/mg suporte) }\end{array}$} & \multirow{2}{*}{$\begin{array}{l}\eta^{*} \\
(\%)\end{array}$} & \multirow[t]{2}{*}{ Aditivo } & \multirow{2}{*}{$\begin{array}{c}\text { Concentração } \\
\text { de lipase } \\
\text { (U/g suporte) }\end{array}$} & \multirow{2}{*}{$\begin{array}{c}\text { Atividade } \\
\text { (U/ mg suporte) }\end{array}$} & \multirow{2}{*}{$\begin{array}{l}\eta^{*} \\
(\%)\end{array}$} \\
\hline & $\mathrm{x}_{1}$ & $\mathrm{x}_{2}$ & & & & & & & & \\
\hline 1 & -1 & -1 & PEG-10.000 & 150 & 27,2 & 15,6 & PEG-10.000 & 150 & 27,2 & 15,6 \\
\hline 2 & +1 & -1 & ABS & 150 & 38,3 & 23,6 & PEG-1.500 & 150 & 109,5 & 59,6 \\
\hline 3 & -1 & +1 & PEG-10.000 & 450 & 33,5 & 7,1 & PEG-10.000 & 450 & 33,5 & 7,1 \\
\hline 4 & +1 & +1 & ABS & 450 & 153,2 & 32,2 & PEG-1.500 & 450 & 198,5 & 41,9 \\
\hline 5 & -1 & 0 & PEG-10.000 & 300 & 42,2 & 14,3 & PEG-10.000 & 300 & 42,2 & 14,3 \\
\hline 6 & +1 & 0 & ABS & 300 & 79,5 & 25,9 & PEG-1.500 & 300 & 104,5 & 31,9 \\
\hline 7 & 0 & -1 & Ausente & 150 & 17,7 & 10,1 & Ausente & 150 & 17,7 & 10,1 \\
\hline 8 & 0 & +1 & Ausente & 450 & 57,6 & 10,3 & Ausente & 450 & 57,6 & 10,3 \\
\hline 9 & 0 & 0 & Ausente & 300 & 50,3 & 17,3 & Ausente & 300 & 50,3 & 17,3 \\
\hline
\end{tabular}

\footnotetext{
* calculado de acordo com a Equação 1.
} 

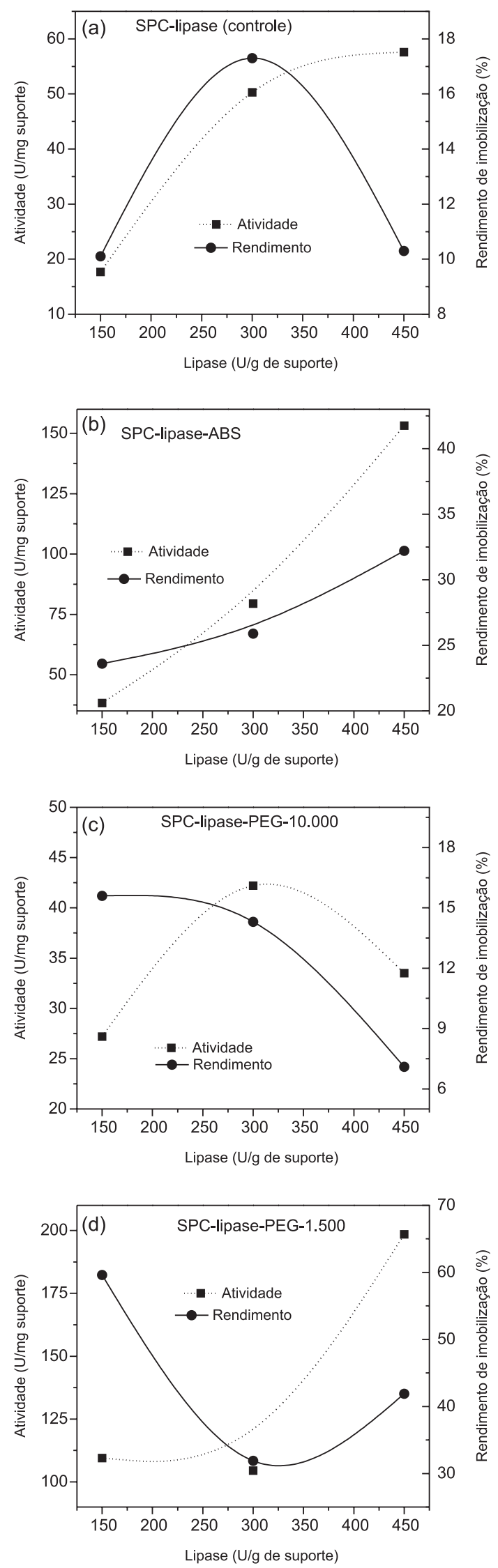

Figura 1. Influência da concentração de lipase (U/g suporte) utilizada na etapa de imobilização na atividade hidrolítica do derivado imobilizado e no rendimento de imobilização empregando sílica de porosidade controlada na presença e ausência de aditivos com uma redução considerável de lipase utilizada na etapa de imobilização (150 U/g de suporte).

\section{Análise estatística}

Os resultados obtidos para os rendimentos de imobilização foram analisados pelo programa STATGRAPHICS versão 6.0. Os valores das estimativas dos efeitos, erros-padrão e do teste t de Student's para o rendimento de imobilização utilizando como aditivos PEG10.000 e ABS (Matriz A) e PEG-10.000 e PEG-1.500 (Matriz B), são apresentados nas Tabelas 2 e 3, respectivamente.

Tabela 2. Efeitos calculados, estimativa de erro e valores do teste t de Student's para o rendimento de imobilização da lipase em sílica de porosidade controlada na presença de PEG-10.000 e ABS

\begin{tabular}{lrcc}
\hline Fonte & Efeito & Erro & valores t \\
\hline Média & 14,58 & $\pm 2,02$ & 7,22 \\
$x_{1}$ (Aditivo) & 15,24 & $\pm 2,21$ & $6,89^{\mathrm{a}}$ \\
$x^{2}{ }_{1}$ (Aditivo) & 14,80 & $\pm 3,83$ & $3,86^{\mathrm{a}}$ \\
$x_{2}$ (Lipase) & 0,08 & $\pm 2,21$ & 0,038 \\
$x^{2}{ }_{2}$ (Lipase) & $-6,04$ & $\pm 3,83$ & 1,58 \\
$x_{1} \cdot x_{2}$ & 8,52 & $\pm 2,71$ & $3,15^{\mathrm{b}}$ \\
\hline
\end{tabular}

${ }^{\mathrm{a}} \mathrm{p}<0,05,{ }^{\mathrm{b}} \mathrm{p}<0,01$

Tabela 3. Efeitos calculados, estimativa de erro e valores do teste $\mathrm{t}$ de Student's para o rendimento de imobilização da lipase em sílica de porosidade controlada na presença de PEG com diferentes massas moleculares

\begin{tabular}{lrcc}
\hline Fonte & Efeito & Erro & valores t \\
\hline Média & 8,40 & $\pm 7,61$ & 1,10 \\
$x_{1}$ (Aditivo) & 31,97 & $\pm 8,33$ & $3,83^{\mathrm{a}}$ \\
$x_{1}{ }_{1}$ (Aditivo) & 31,84 & $\pm 14,44$ & 2,20 \\
$x_{2}$ (Lipase) & $-6,34$ & $\pm 8,33$ & $-0,76$ \\
$x_{2}{ }_{2}$ (Lipase) & 12,48 & $\pm 14,44$ & $-0,86$ \\
$x_{1} \cdot x_{2}$ & $-4,56$ & $\pm 10,21$ & 0,44 \\
\hline
\end{tabular}

${ }^{\mathrm{a}} \mathrm{p}<0,05$

Para a matriz A, verifica-se que a variável aditivo $\left(x_{1}\right)$ e seu termo quadrático, bem como a interação entre o aditivo e a concentração da lipase $\left(x_{T} x_{2}\right)$, apresentaram influência significativa ao nível de $95 \%$ de confiança ${ }^{11}$. Nesta análise, a existência do efeito de segunda ordem confirma os dados descritos na literatura, com relação ao efeito estabilizante da albumina, minimizando a desativação da enzima durante sua fixação em suportes sólidos ${ }^{12}$.

Com relação a matriz B, verifica-se pelo teste t de Student's que a concentração de lipase e sua interação com o aditivo não apresentaram influência significativa ao nível de $95 \%$ de confiança. Somente a variável $x_{1}$ (aditivo) mostrou-se significativa $(\mathrm{p}<0,05)$ no rendimento de imobilização.

Baseados nas respostas avaliadas foram desenvolvidos modelos matemáticos para ambas as matrizes. As análises foram efetuadas para ajustar as funções respostas com os dados experimentais e as Equações 5 e 6 expressam os modelos, para as matrizes A e B, respectivamente, nas quais as variáveis apresentam os valores codificados, representando o rendimento de imobilização ( $\hat{y})$ como função do aditivo $\left(x_{1}\right)$ e da concentrações de lipase $\left(x_{2}\right)$.

$\hat{y}=12,56+7,62 x_{1}+7,39 x^{2}{ }_{1}+4,26 x_{1} x_{2}$

$\hat{y}=31,97+31,84 x_{1}$ 
Analisando as Tabelas 4 e 5, observa-se que os modelos foram adequados para descrever as relações entre as respostas e as variáveis estudadas.

Tabela 4. Análise de variância do modelo matemático representativo do rendimento de imobilização da lipase em sílica de porosidade controlada na presença de PEG-10.000 e ABS

\begin{tabular}{lcccrc}
\hline Fonte & $\begin{array}{c}\text { Soma } \\
\text { quadrática }\end{array}$ & $\begin{array}{c}\text { Graus de } \\
\text { liberdade }\end{array}$ & $\begin{array}{c}\text { Média } \\
\text { quadrática }\end{array}$ & $\mathrm{F}^{*}$ & $\mathrm{p}^{* *}$ \\
\hline$x_{1}$ & 348,23 & 1 & 348,23 & 43,21 & 0,0012 \\
$x^{2}{ }_{1}$ & 109,47 & 1 & 109,47 & 13,59 & 0,0142 \\
$x_{1} \cdot x_{2}$ & 72,67 & 1 & 72,67 & 9,01 & 0,0300 \\
Erro & 40,28 & 5 & 8,05 & & \\
Total & 570,67 & 8 & & & \\
\hline
\end{tabular}

$\mathrm{R}^{2}=0,93$; *F: teste estatístico de comparação da variância nos ensaios, permitindo a avaliação da qualidade do ajuste do modelo; ** p: teste estatístico para estimativa do intervalo de confiança do modelo.

Tabela 5. Análise de variância do modelo matemático que representa o rendimento de imobilização da lipase em sílica de porosidade controlada na presença de PEG com diferentes massas moleculares

\begin{tabular}{lrcrrl}
\hline Fonte & $\begin{array}{c}\text { Soma } \\
\text { quadrática }\end{array}$ & $\begin{array}{c}\text { Graus de } \\
\text { liberdade }\end{array}$ & $\begin{array}{c}\text { Média } \\
\text { quadrática }\end{array}$ & $\mathrm{F}^{*}$ & $\mathrm{p}^{* *}$ \\
\hline$x_{1}$ & 1533,12 & 1 & 1533,12 & 14,70 & 0,031 \\
$x^{2}{ }_{1}$ & 506,99 & 1 & 506,99 & 4,86 & 0,11 \\
$x_{2}$ & 60,36 & 1 & 60,36 & 0,57 & 0,50 \\
$x^{2}{ }_{2}$ & 77,92 & 1 & 77,92 & 0,74 & 0,45 \\
$x_{1} \cdot x_{2}$ & 20,84 & 1 & 20,84 & 0,20 & 0,68 \\
Erro & 312,82 & 5 & 104,27 & & \\
Total & 2512,05 & 8 & & & \\
\hline
\end{tabular}

$\mathrm{R}^{2}=0,87$; $\mathrm{F}$ : teste estatístico de comparação da variância nos ensaios, permitindo a avaliação da qualidade do ajuste do modelo; ** p: teste estatístico para estimativa do intervalo de confiança do modelo.

Para a matriz A, a análise de variância e o coeficiente de determinação $R^{2}=0,93$ revelam que o modelo representa bem o procedimento de imobilização, confirmando que os efeitos do aditivo e de interação foram significativos para a faixa experimental avaliada ${ }^{10}$.

Para a matriz B, a validade do modelo proposto foi estatisticamente significativa $(\mathrm{p}=0,05)$ ao nível de $95 \%$ de confiança. O modelo não apresentou falta de ajuste e a determinação do coeficiente de correlação $\left(\mathrm{R}^{2}=0,87\right)$ mostra que $87 \%$ da variabilidade na resposta, em relação à análise dos resultados obtidos, pode ser explicada pelo modelo.

Os valores preditos pelos modelos estão mostrados nas Figuras 2 e 3. Para matriz A (Figura 2), observa-se que o rendimento de imobilização foi maximizado na presença de albumina $\left(x_{1}=1\right)$ e nível alto de concentração de lipase $\left(x_{2}=1\right)$, confirmando assim os valores de p obtidos pela análise de variância (Tabela 4), os quais foram significativos para o efeito do aditivo $(\mathrm{p}=0,001)$ e para a interação entre aditivo e concentração de lipase $(\mathrm{p}=0,03)$, ao nível de confiança de $95 \%(\mathrm{p}<0,05)$.

A representação gráfica da curva de nível (Figura 3), para a matriz $\mathrm{B}$, indica que o rendimento mais elevado $(59,6 \%)$ foi obtido quando PEG-1.500 foi utilizado como agente estabilizante, produzindo uma preparação catalítica altamente ativa $(109,5 \mathrm{U} / \mathrm{mg})$, com uma redução considerável de lipase utilizada na etapa de imobilização (150 U/g de suporte). Nota-se uma tendência crescente da resposta avaliada $(\eta \%)$ com a redução dos níveis dos fatores massa

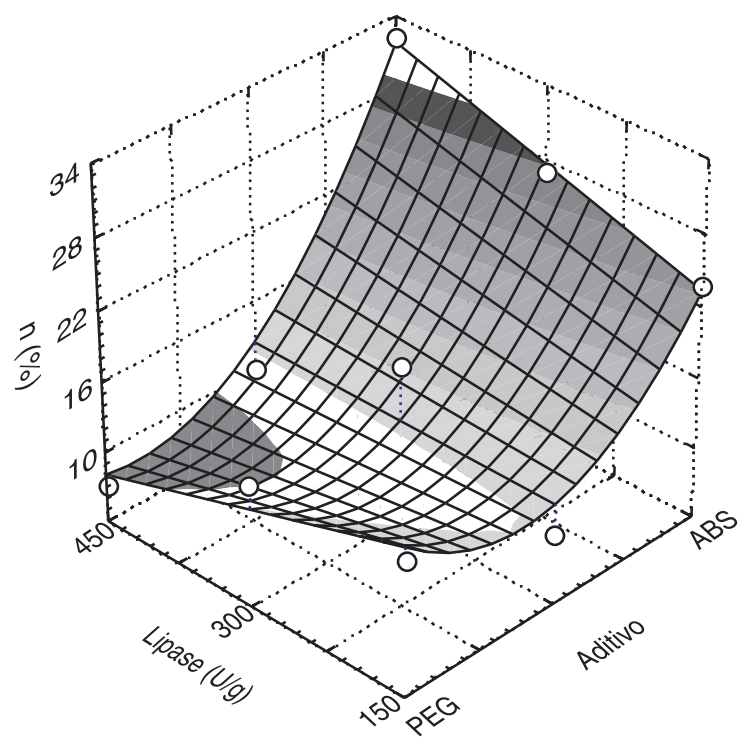

Figura 2. Superfície de resposta para o rendimento de imobilização da lipase em sílica de porosidade controlada na presença de PEG-10.000 e $A B S$, descrita pela Equação 5

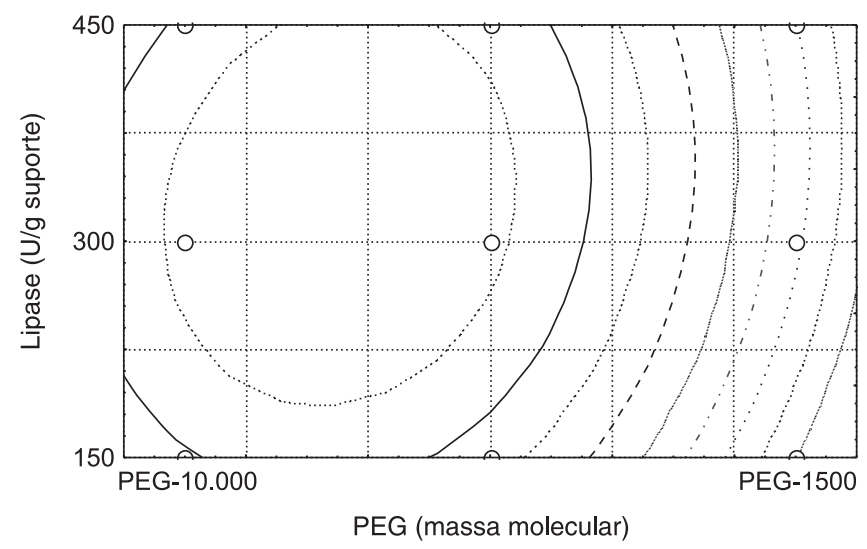

Figura 3. Curva de nível para o rendimento de imobilização da lipase em sílica de porosidade controlada na presença de PEG com diferentes massas moleculares, descrita pela Equação 6

molecular do PEG e concentração da enzima utilizada no procedimento de imobilização.

Entre todos os aditivos testados, apenas o PEG-10.000 não foi efetivo, reduzindo o rendimento de imobilização da lipase em SPC em comparação ao controle. A albumina apresentou efeitos benéficos para todas as concentrações de lipase e o PEG-1.500 foi mais efetivo para concentração de lipase no nível baixo (150 U/g de suporte).

\section{Efeito dos aditivos na atuação dos derivados na catálise em meio orgânico}

Para permitir uma melhor avaliação do efeito dos aditivos testados, os derivados imobilizados mais ativos foram utilizados na síntese do butirato de butila, avaliando a cinética de conversão dos materiais de partida em éster. As sínteses foram realizadas conforme metodologia descrita, sendo os resultados apresentados nas Figuras 4 a-d. Os dados foram comparados com aqueles obtidos com a lipase imobilizada em SPC sem aditivo nas mesmas condições operacionais. 
A Figura 4a mostra que, no caso da utilização do controle (lipase imobilizada em SPC na ausência de aditivos) a máxima concentração obtida para o butirato de butila foi de $150 \mathrm{mM}$, após $24 \mathrm{~h}$ de reação. Quando se empregou a lipase imobilizada na presença dos aditivos (Figuras 4 b-d), verificou-se um acréscimo em concentração de aproximadamente 1,5 vezes (240-250 mM). Estes resultados evidenciam o efeito estabilizante dos aditivos testados e confirmam dados da literatura, os quais indicam um aumento considerável da atividade catalítica por meio do tratamento do suporte com polímeros orgânicos ou proteínas não enzimáticas ${ }^{3}$. Esses tipos de materiais provavelmente protegeram a enzima de efeitos de agregação ou de desnaturação devido à presença dos silanos usados na formação da matriz sílica.

Comportamento semelhante foi obtido por Wu e colaboradores ${ }^{13}$, empregando PEG juntamente com óxido propileno para aumentar a hidrofobicidade e introduzir um braço espaçador na estrutura do suporte. A atividade específica máxima da lipase de Candida rugosa imobilizada foi duas vezes superior na esterificação do ácido olêico e lauril álcool em hexano. Villeneuve et al. ${ }^{12}$ também obtiveram resultados similares no caso particular da reação de transesterificação do ácido esteárico com óleo de palma, empregando uma lipase de Rhizopus sp. imobilizada em sílica na presença de PEG.

\section{Estabilidade operacional}

O perfil de estabilidade operacional dos derivados imobilizados em SPC, na ausência e presença de PEG-1.500, foi estimado por meio de testes de esterificação (batelada consecutiva). Para estimativa do tempo de meia-vida $\left(\mathrm{t}_{1 / 2}\right)$, as atividades relativas foram graficadas em função do tempo (Figura 5) e por regressão linear foram obtidas as Equações 7 e 8, para a lipase imobilizada em SPC na ausência e na presença de PEG-1.500, respectivamente.

$\mathrm{t}_{1 / 2}=102,24-0,81 \mathrm{x}$

$\mathrm{t}_{1 / 2}=103,00-0,30 \mathrm{x}$

O derivado imobilizado, obtido na ausência de PEG-1.500, apresentou um tempo de meia-vida de $64,5 \mathrm{~h}$, enquanto que o derivado preparado na presença desse aditivo revelou um tempo de meia-vida de $176 \mathrm{~h}$.

Com os resultados dos testes catalíticos em regime de batelada consecutiva foi possível confirmar que a lipase imobilizada obtida na presença de PEG-1.500, além de apresentar uma atividade catalítica maior, foi o sistema imobilizado mais estável. Esses resultados indicaram que a estratégia proposta foi eficiente, promovendo um aumento da ordem de 2,7 vezes no tempo de meia-vida da preparação experimental de lipase imobilizada em SPC.

A utilização de PEG como braço espaçador em meio orgânico torna-se, portanto, uma das novas estratégias para estabilizar o sistema imobilizado em reações de síntese, provavelmente devido ao fato deste braço espaçador minimizar as interações hidrofóbicas e atrações eletrostáticas entre a proteína e o suporte ${ }^{14}$.

Deve-se também salientar que a utilização do aditivo PEG-1.500 protege a enzima dos efeitos de desnaturação, sem interferir na velocidade de reação de esterificação. Sendo, entretanto, o PEG solúvel em heptano, é provável que esta propriedade tenha contribuído favoravelmente na partição do substrato para a fase sólida, reduzindo eventuais resistências difusionais da enzima imobilizada.

O recobrimento com PEG representa um compromisso entre as forças atrativas de ligação ao suporte e as forças repulsivas, devido ao efeito estérico produzido pela interação das cadeias do polímero em solução ${ }^{5,12}$. Sabe-se que na sua forma livre, em geral, o PEG tende a agregar proteínas em solução o que, possivelmente, deve pro-
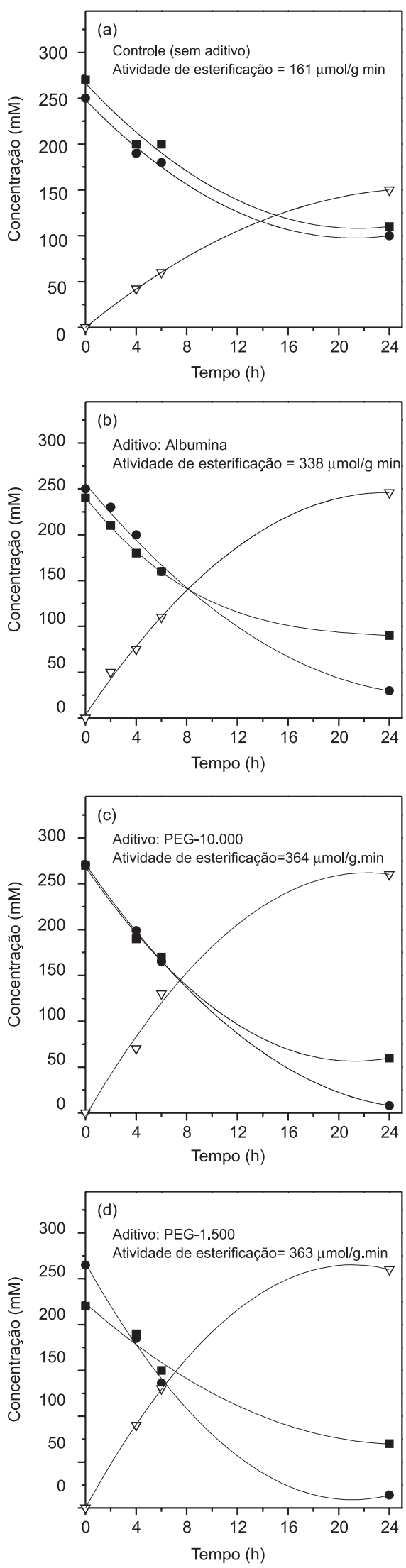

Figura 4. Perfil da síntese do butirato de butila ( $\nabla)$ por esterificação do $n$ butanol (ם) com ácido butírico (-) catalisada por lipase imobilizada em $S P C$ na ausência (a) e presença de aditivos $(b-d)$. As reações foram realizadas em substratos contendo n-butanol (300 mM), ácido butírico (300 mM) em heptano a $37{ }^{\circ} \mathrm{C}$ com massa seca de enzima igual a $0,85 \mathrm{~g}$ 


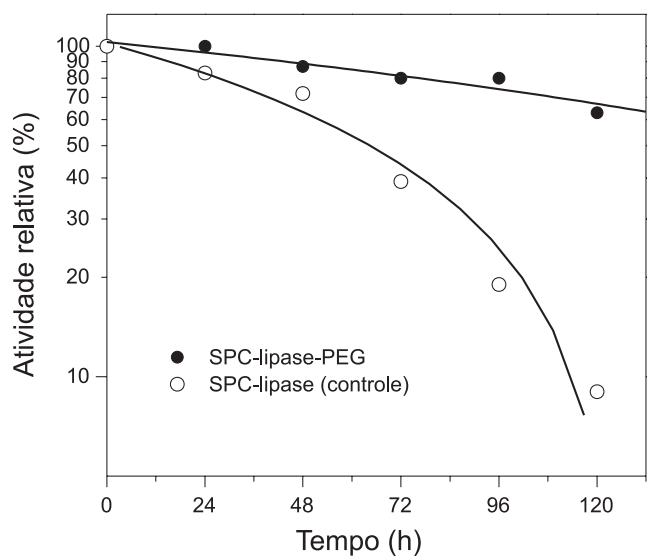

Figura 5. Determinação do tempo de meia-vida das preparações de lipase imobilizada em SPC obtidas por ligação covalente na presença e ausência de PEG-1.500

mover a oclusão das enzimas e a ligação da camada protetora do polímero ao suporte ${ }^{14}$.

Por outro lado, de acordo com a literatura, o polietilenoglicol é solúvel em água, tolueno e outros solventes, entretanto insolúvel em hexano, éter e etilenoglicol ${ }^{14}$. Baseando-se no procedimento de imobilização adotado, as etapas de lavagem do sistema imobilizado realizadas com hexano, para a retirada de resíduos, alcançaram o objetivo desejado sem promover o desligamento da enzima do suporte devido à proteção do aditivo. A condição de solubilidade do PEG1.500 em outros solventes favoreceu a reação padrão de síntese de ésteres adotada neste trabalho, na qual o substrato utilizado teve como base o solvente orgânico heptano. Este fato pode ter favorecido o aumento do tempo de meia-vida do sistema imobilizado de 64,5 para $176 \mathrm{~h}$, quando foi utilizado PEG-1.500 para minimizar os efeitos negativos de resistências difusionais.

\section{CONCLUSÕES}

Neste trabalho, foram desenvolvidas estratégias para otimizar a estabilidade operacional de uma preparação de lipase imobilizada em sílica de porosidade controlada. Para atingir este propósito, foram testados diferentes tipos de agentes estabilizantes, com a finalidade de proteger a enzima de efeitos de agregação ou desnaturação, que ocorrem devido à presença dos silanos usados durante a formação da matriz de sílica. Os aditivos usados como estabilizantes foram albumina e polietilenoglicol e seus efeitos foram comparados ao controle (lipase imobilizada sem aditivo).
A metodologia de planejamento experimental foi utilizada para selecionar o aditivo mais efetivo, utilizando como variável resposta o rendimento da imobilização. Entre os aditivos testados, apenas o PEG10.000 não foi efetivo, reduzindo o rendimento de imobilização da lipase em SPC em comparação ao controle. A albumina apresentou efeitos benéficos para todas as concentrações de lipase testadas, sendo obtido um valor máximo de atividade lipolitíca de 153,2 U/mg de suporte para uma concentração de lipase da ordem de $450 \mathrm{U} / \mathrm{g}$ de suporte. Rendimentos mais elevados $(59,6 \%)$ foram obtidos quando PEG-1.500 foi utilizado como agente estabilizante, produzindo uma preparação catalítica altamente ativa $(109 \mathrm{U} / \mathrm{mg})$ com uma redução considerável de lipase utilizada na etapa de imobilização (150 U/g de suporte). A estabilidade operacional do derivado imobilizado na presença de PEG-1.500 foi determinada na síntese de butirato de butila em regime de bateladas consecutivas. Adotando a estratégia proposta neste trabalho, o tempo de meia-vida da lipase imobilizada em SPC foi aumentado em 2,7 vezes, quando comparado com o tempo de meiavida da lipase imobilizada em SPC sem aditivo.

\section{AGRADECIMENTOS}

Os autores agradecem os auxílios financeiros recebidos da CAPES, CNPq e FAPESP.

\section{REFERENCIAS}

1. Gonçalves, A. M.; Schucht, E.; Matthijs, G.; Aires Barros, M. R.; Cabral, J. M. S.; Gil, M. H.; Enzyme Microb. Technol. 1999, 24, 60.

2. Wehtje, E.; Adlercreutz, P.; Mattiasson, B.; Biotechnol. Bioeng. 1993, 41, 171.

3. Reetz, M.T.; Zonta, A.; Simpelkamp, J.; Biotechnol. Bioeng. 1996, 49, 527.

4. Trintafyllou, A. O.; Wehtje, E.; Adlercreutz, P.; Mattiasson, B.; Biotechnol. Bioeng. 1995, 45, 406.

5. Rocha, J. M.; Gil, M. H.; Garcia, F. A. P.; J. Biotechnol. 1998, 66, 61.

6. Bosley, J. A.; EP pat. 424,130 1991.

7. Zanin, G. M.; Tese de Doutorado, Universidade Estadual de Campinas, Brasil, 1989.

8. Baron, M.; Florêncio, J. A.; Zanin, G. M.; Ferreira, A. G.; Ennes, R.; Fontana, J. D.; Appl. Biochem. Biotechnol. 1996, 57/58, 605.

9. Soares, C. M. F.; de Castro, H. F.; de Moraes, F. F.; Zanin, G. M.; Appl. Biochem. Biotechnol. 1999, 77, 745.

10. Bradford, M. M. A.; Anal. Biochem. 1976, 72, 248.

11. Box, G. E. P.; Hunter, W. G.; Hunter, J. S.; Statistics for Experimenters: An Introduction to Design, Wiley \& Sons Inc.: New York, 1978, p. 653.

12. Villeneuve, P.; Muderhwa, J. M.; Graille, J. M.; Haas, M. J.; J. Mol. Catal. B: Enzym. 2000, 9, 11.

13. Wu, J. C.; Zhang, G. F.; He, Z. M.; Biotechnol. Lett. 2001, 23, 211.

14. Harris, J. M. Em Poly (Ethylene glycol) Chemistry: Biotechnical and Biomedical Applications; Plenum Press: New York, 1992, p. 228. 